\title{
Interface entre as áreas de operações e meio ambiente: estudo de casos sobre os pontos de contato e seus potenciais conflitos
}

\author{
Interface between operations and environment areas: \\ case studies on the contact points and potential conflicts
}

\author{
Guilherme Salatine Pereira ${ }^{1}$ \\ Ana Beatriz Lopes de Sousa Jabbour ${ }^{1}$
}

\begin{abstract}
Resumo: Esta pesquisa tem como objetivo identificar como os pontos de contato entre as áreas de operações e meio ambiente de empresas de manufatura estão sendo explorados, e, também, identificar como eventuais conflitos, que possam surgir durante essa interação, estão sendo mediados. Foram escolhidas grandes empresas de manufatura localizadas no Estado de São Paulo para compor um estudo de casos, e as informações foram obtidas por meio de entrevistas, dados secundários e observações in loco nas empresas. A análise foi realizada por meio da metodologia cross case, observando-se os aspectos de autoridade, atividade e comunicação na estrutura organizacional das empresas. Os resultados apontam que as organizações estudadas exploram todos os pontos de contatos elencados na literatura, com destaque especial para a atividade de modificação de processo de fabricação, por haverem procedimentos formais que requerem o aval da área de meio ambiente. Quanto aos conflitos, nenhum foi destacado pelas empresas estudadas, pois essas mantêm relações colaborativas e/ou integrativas entre as áreas de operações e meio ambiente. Assim, concluiu-se que o estágio de maturidade ambiental das empresas estudadas tende a ser um potencial fator para a ausência de conflitos entre as áreas, como também a presença de todos os pontos de contato levantados.
\end{abstract}

Palavras-chave: Gestão de operações; Gestão ambiental; Estrutura organizacional; Integração.

\begin{abstract}
This research aims to identify how contact points between operations and environment areas have been happening in manufacturing companies, and also identify how any conflicts arising during that interaction have been mediated. The case study was composed by large manufacturing companies located in São Paulo state. The analysis was conducted using the cross case methodology, observing the companies'organizational structure aspects of authority, activity and communication. The results show that the organizations studied explore all contacts points listed in the literature, with particular attention to manufacturing process modification activity, since there are formal procedures that require the approval of the environmental area. As for conflicts, none were highlighted by the companies studied, as these maintain collaborative or integrative relationships between operations and environment areas. Thus, it is concluded that the environmental maturity stage of the companies studied tends to be a potential factor in the absence of conflicts between areas, as well as the presence of all contact points raised.
\end{abstract}

Keywords: Operations management; Environmental management; Organizational structure; Integration.

\section{Introdução}

Organizações fazem parte da vida cotidiana e são criadas para facilitar a execução de tarefas que dificilmente seriam desempenhadas por indivíduos isolados. Cada organização tem a capacidade de influenciar indivíduos e a sociedade como um todo. Os impactos causados podem ser positivos ou negativos, incluindo aspectos econômicos, sociais e físicos. Como impacto físico entende-se mudança na paisagem ao redor da organização, e sua relação com os recursos naturais existentes e o meio ambiente (Hall, 2004).
Organizações são compostas por processos que podem ser divididos e agrupados em atividades semelhantes, criando as chamadas áreas funcionais. Assim, cada grupo de tarefas é desempenhado por unidades específicas dentro de uma organização (Sobral \& Peci, 2008).

A preocupação da área de operações, e de organizações como um todo, em reduzir seus impactos ambientais negativos tem sido crescente desde a segunda metade dos anos 1990, devido à pressão exercida por

\footnotetext{
${ }^{1}$ Departamento de Engenharia de Produção, Faculdade de Engenharia de Bauru, Universidade Estadual Paulista - UNESP, Av. Engenheiro Luiz Edmundo Corrijo Coube, 14-01, Vargem Limpa, CEP 17033-360, Bauru, SP, Brasil, e-mail: guilherme.salatine@outlook.com; abjabbour@feb.unesp.br
}

Recebido em Jun. 4, 2014 - Aceito em Ago. 4, 2015

Suporte financeiro: Fundação de Amparo à Pesquisa do Estado de São Paulo (FAPESP), processo nº 2013/07619-6. 
investidores e parceiros para que empresas tornem seus processos mais limpos e enxutos (Fryxell \& Vryza, 1999; Despeisse et al., 2012).

Para Donaire (1999), a função operações de uma organização de manufatura ocupa uma posição de destaque no que se refere à geração de impactos físicos negativos, quando comparada às áreas com perfis administrativos, como o departamento financeiro e recursos humanos, por exemplo. Para Despeisse et al. (2012), a área de operações não pode ficar indiferente aos seus impactos no meio ambiente, e deve buscar meios para tornar seus processos mais sustentáveis.

Uma forma de reduzir impactos negativos causados por organizações de manufatura ao meio ambiente é aumentar a presença de profissionais e de práticas relacionadas ao meio ambiente em áreas como pesquisa e desenvolvimento de produtos, produção, manutenção, tratamento de rejeitos, entre outras que compõem a área de operações da organização, ou seja, promover uma integração interfuncional entre operações e meio ambiente (Donaire, 1999).

Existem estudos que tiveram como alvo analisar as interdependências funcionais com operações, porém o foco maior dessas pesquisas estava nos pontos de contato entre aquela área e marketing (Tang, 2010), entre operações e logística (Xiong, 2011) e entre a tríade operações-marketing-logística (Lombardi et al., 2012).

Segundo Wagner (2007), os estudos teóricos sobre a interdependência entre operações e meio ambiente estão limitados a uma perspectiva gerencial, sem uma conexão com as ferramentas práticas que poderiam alcançar tal relacionamento mútuo. Galeazzo et al. (2014) identificaram poucos estudos voltados para as decisões dentro da relação entre meio ambiente e operações. Ainda, a função operações necessita ampliar mais seu entendimento sobre as práticas de produção mais ambientalmente amigáveis (Baines et al., 2012).

Portanto, o estudo da interface entre operações e meio ambiente pode representar uma oportunidade de compreender como duas importantes áreas funcionais têm explorado potenciais benefícios mútuos da cooperação entre ambos os departamentos, e verificar quais são os eventuais conflitos causados pela interdependência funcional. Assim, essa pesquisa busca: identificar como empresas de manufatura estão explorando os pontos de contato entre operações e meio ambiente; e como os potenciais conflitos, devidos a essa interdependência, estão sendo mediados.

A seguir, é apresentada a revisão de literatura, com os principais conceitos necessários ao estudo. Também é apresentada a metodologia da pesquisa, bem como seus resultados e discussões, seguidos da conclusão.

\section{Referencial teórico}

\subsection{Estrutura organizacional}

O conceito de organização deve ser bastante amplo para abranger desde empresas multinacionais, até organizações civis, militares e as sem fins lucrativos. Assim, organizações podem ser definidas como entidades sociais orientadas segundo objetivos e projetadas de acordo com uma estrutura, relacionando-se com o ambiente externo (Daft, 2010).

A estrutura de uma organização assume duas dimensões, uma formal e baseada no desenvolvimento de um arranjo dos recursos, de modo a maximizar a eficiência; e uma estrutura informal, que é resultado da interação entre os membros da organização realizada fora dos canais oficiais de comunicação da organização (Rank, 2008). Ou seja, enquanto a estrutura formal segue uma linha pré-estabelecida de autoridade entre líder e liderados, a estrutura informal não se limita as relações documentadas, surgindo da interação entre os trabalhadores, e sendo solidificada com o tempo. A estrutura formal é desenhada para facilitar a padronização dos processos e ações, sendo que a estrutura informal se torna mais importante quando surgem problemas inesperados (Krackhardt \& Hanson, 1993). Para esta pesquisa, considerou-se apenas a estrutura formal da organização, a fim de se analisar os processos já estabelecidos e realizados pelas empresas.

A estrutura formal de uma organização é um conjunto de relacionamentos entre os agentes e suas respectivas posições organizacionais, com o propósito de alcançar um objetivo (Rank, 2008). A estrutura formal é composta por três subsistemas distintos, porém complementares. O subsistema de autoridade abrange as relações hierárquicas formadas entre os membros da organização. O subsistema de atividades reúne o conjunto de processos realizados por cada membro. Já o subsistema de comunicação é o que torna possível a interação entre os subsistemas já citados (Vasconcellos \& Hemsley, 2002). A Figura 1 ilustra a relação entre a estrutura organizacional e seus subsistemas.

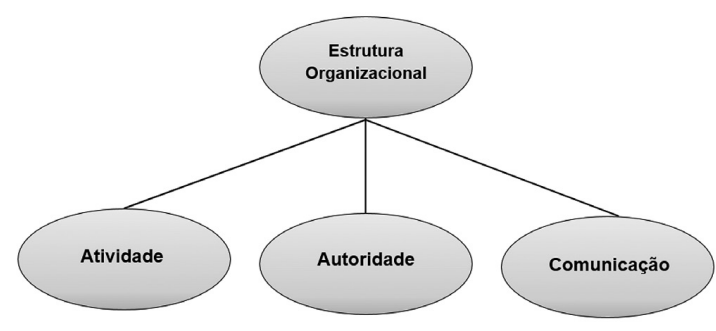

Figura 1. A estrutura organizacional formal e seus subsistemas. Fonte: Baseado em Vasconcellos \& Hemsley (2002). 
A estrutura formal da organização é descrita por meio de vários fatores como: departamentalização, centralização, amplitude de controle, grau de formalização e sistema de comunicação a ser utilizado. Estruturas mais tradicionais apresentam alto grau de formalização, elevada especialização de recursos, comunicação verticalizada e utilização de critérios tradicionais de departamentalização (Vasconcellos \& Hemsley, 2002).

A departamentalização é o processo de agrupamento de recursos para facilitar sua administração. Os critérios mais tradicionais são: funcional, geográfico ou territorial, por processo, por clientes e por produto (Sobral \& Peci, 2008). O critério de departamentalização funcional é tido como mais intuitivo, agrupando as tarefas de acordo com as funções organizacionais, como departamento de marketing, de pesquisa e desenvolvimento, de operações; ou áreas técnicas, como departamento de hidráulica, de engenharia entre outras (Vasconcellos \& Hemsley, 2002; Sobral $\&$ Peci, 2008).

A representação visual da estrutura de uma organização é chamada de organograma (Sobral \& Peci, 2008). O organograma ilustra todo o conjunto de atividades e processos de uma organização, assim como desenha relacionamentos entre os cargos e níveis hierárquicos (Daft, 2010).

\subsection{1 Área de operações}

Dentro da estrutura funcional da organização está a área de operações. Esta área funcional consiste em todas as atividades relacionadas de forma direta à elaboração e manufatura de produtos ou do oferecimento de serviços (Stevenson, 2011). Para Williams (2007), essas atividades incluem o design e a criação, a manufatura, e até mesmo a entrega dos bens produzidos.

A área de operações de uma empresa é vital para o seu funcionamento, pois, além de oferecer o principal resultado da organização, concentra grande quantidade de recursos investidos, e sua gestão influencia diretamente a qualidade, o custo, e o impacto ambiental das mercadorias e serviços (Williams, 2007).

\subsection{2 Área de meio ambiente}

Aárea de meio ambiente tem emergido rapidamente como um departamento essencial em muitas indústrias, devido às mudanças na legislação ambiental propostas pelo Governo, e a oportunidade de diferenciar um produto, torná-lo ambientalmente mais correto e assim conquistar os consumidores sensíveis às questões ambientais (Donaire, 1999; Fryxell \& Vryza, 1999).

A importância da área de meio ambiente também vem crescendo dentro das empresas, principalmente das de manufatura. Uma pesquisa divulgada em 2011 pelo Boston Consulting Group, com 3000 líderes corporativos em 113 países, concluiu que o interesse pelas questões ambientais cresceu em todos os setores e localidades pesquisados. Também foi verificado que as empresas que já estão usufruindo dos benefícios trazidos pelas atividades sustentáveis estão mudando sua estrutura organizacional, processos, unidades de negócio para que suas práticas se tornem ainda mais sustentáveis (Haanaes et al., 2012).

Recai sobre esta área o planejamento e a execução de ações que deverão atingir os objetivos da organização em termos de performance ambiental (Jabbour, 2009). A extensão e profundidade dessas ações variam de acordo com o nível de preocupação da organização sobre os impactos causados por seus processos, bem como o nível de proatividade ambiental que a empresa possui (Jabbour \& Santos, 2006).

Corazza (2003) identificou duas formas de classificação da integração da área de meio ambiente com o restante da organização, a saber:

- Integração limitada: se caracteriza pela criação do departamento de meio ambiente, atribuindo prestígio por parte da alta administração. Porém, se essa importância não é efetiva, o departamento de meio ambiente não consegue prosperar para uma abordagem mais proativa das atividades.

- Integração matricial: a área de meio ambiente passa a apoiar os demais departamentos da organização, com especial ênfase nas atividades de gestão, inovação, produção e recursos humanos.

A integração matricial é a que apresenta maior nível de proatividade, sendo assim, empresas que possuem uma integração matricial entre seus departamentos e meio ambiente devem possuir melhor desempenho ambiental, o que se traduz em maior responsabilidade para o gestor de meio ambiente, com maior gama de atividades desenvolvidas por esse.

Para Donaire (1999), as atividades básicas que deveriam ser desempenhadas por um gestor da área de meio ambiente são: o processo de gestão e implantação da política ambiental da empresa; o controle e monitoramento dos poluentes; a prestação de assessoria técnica em meio ambiente para as demais áreas da organização; o acompanhamento da legislação ambiental; o treinamento dos indivíduos ligados à área de meio ambiente; e ser o representante da empresa em órgãos e divisões que regulam a atuação ambiental, bem como ser a o porta-voz para todos os assuntos relacionados a meio ambiente para com a comunidade. Essas atribuições estão ligadas ao subsistema autoridade. 


\subsection{Interface interfuncional entre operações e meio ambiente}

O relacionamento entre diferentes áreas de uma organização pode ocorrer tendo a forma de interação, colaboração, ou integração interfuncional. O Quadro 1 relaciona as formas de relacionamento com os recursos característicos.

A interação interfuncional ocorre pela troca de informações entre ambas as áreas. Já a colaboração envolve os departamentos por meio de metas conjuntas, e objetivos comuns a ambos os departamentos. Em um estágio mais avançado, uma organização pode possuir equipes multidisciplinares, em que todos os recursos e informações são compartilhados; esse estágio configura a integração interfuncional (Kahn, 2001). Esses relacionamentos representam o subsistema de comunicação da estrutura organizacional, ou seja, a forma com que um departamento se relaciona com o outro está ligada pela adoção de meios mais ou menos efetivos e formais de comunicação organizacional.

Mais especificamente, a relação de interdependência entre as áreas de operações e meio ambiente ganhou importância por influenciar a competitividade global das organizações e prover benefícios para ambas as áreas funcionais (Durham, 2002). Na região de aproximação entre as áreas funcionais, desenvolvem-se os chamados pontos de contato (Lombardi et al., 2012).

Atividades relacionadas ao projeto do produto e o processo produtivo são de responsabilidade da área de operações (Williams, 2007). O relacionamento com a área de meio ambiente pode ocorrer durante aquelas atividades, com produtos, a partir de design que facilite a reciclagem/reuso/remanufatura, ou que não utilize materiais perigosos ou contaminantes; $\mathrm{e}$ com processo, pela busca de processos mais eficazes e eficientes, que reduzam as perdas e o desperdício; e, também, se racionalizando o uso de embalagens.

Os meios pelos quais são possíveis haver relacionamentos entre as áreas de operações e de meio ambiente são listados no Quadro 2, contendo ainda uma breve caracterização sobre os pontos de contato e uma relação de autores que apoiam tais pontos.

Os pontos de contados apresentados representam o subsistema de atividades da estrutura organizacional, ou seja, são as atividades desempenhadas pela organização, segundo sua estrutura, que geram uma interação entre as áreas de operações e meio ambiente.

Por possuírem responsabilidades distintas, por vezes, as áreas de operações e meio ambiente podem ser adversárias (Hanna et al., 2000). Porter \& Van Der Linde (1995) veem a postura da empresa como geradora dos conflitos entre as áreas de meio ambiente e operações quando postergam a solução de seus problemas ambientais e adequações a novas regulamentações, ao invés de investirem em inovação e tomarem uma posição que antecipe as preocupações ecológicas. Para Gupta (1995), administradores têm postergado a implementação de ações ambientalmente amigáveis devido ao seu custo imediato de aquisição, porém os benefícios a longo prazo trariam retornos financeiros positivos para a organização.

O Quadro 3 apresenta alguns dos potenciais conflitos que podem ocorrer durante a interdependência funcional entre as áreas de operações e meio ambiente, juntamente com uma breve descrição e os principais autores que os identificaram.

Os conflitos poderiam ser reduzidos com uma visão holística da empresa e de seus processos, assim como com maior orientação para que a organização passe a ser vista como uma referência positiva pela comunidade, por meio de suas boas práticas ambientais (Corbett \& Klassen, 2006; Nash, 2009).

\section{Metodologia}

\subsection{Objeto de estudo}

Para esta pesquisa foram selecionadas empresas de grande porte de manufatura que atuam no Estado de São Paulo. Três empresas (Empresa A, Empresa B, e Empresa C) foram escolhidas por apresentarem práticas ambientais reconhecidas pela sociedade. Essas boas práticas seriam traduzidas pela adoção da certificação ISO 14001; ou da participação no Índice de Sustentabilidade Empresarial (ISE), promovido pela BM\&F Bovespa; ou ainda, pela expedição do relatório de sustentabilidade segundo as diretrizes definidas pela Global Reporting Initiative (GRI, 2015).

Quadro 1. Formas de relacionamento entre os departamentos de uma organização.

\begin{tabular}{|l|l|}
\hline \multicolumn{1}{|c|}{ Forma de relacionamento } & \multicolumn{1}{c|}{ Recursos utilizados } \\
\hline Interação & $\begin{array}{l}\text { - Reuniões formais; } \\
\text { - Comunicação oficial como: memorandos, relatórios, entre outros documentos. }\end{array}$ \\
\hline Colaboração & $\begin{array}{l}\bullet \text { Metas conjuntas; } \\
\text { - Mesmos objetivos; } \\
\text { - Compartilhamento parcial de informações e recursos. }\end{array}$ \\
\hline Integração interfuncional & $\begin{array}{l}\text { - Equipes multidisciplinares; } \\
\text { - Compartilhamento total de informações e recursos. }\end{array}$ \\
\hline
\end{tabular}

Fonte: Baseado em Kahn (2001). 
Quadro 2. Pontos de contato entre operações e meio ambiente.

\begin{tabular}{|c|c|c|}
\hline Ponto de Contato & Características & Principais Autores \\
\hline Design Sustentável & $\begin{array}{l}\text { O projeto de novos produtos ou de melhoria dos } \\
\text { produtos já existentes leva em conta preocupações } \\
\text { ambientais como a escolha de matérias-primas de } \\
\text { fontes renováveis. Bem como o desenvolvimento de } \\
\text { um projeto que facilite a reciclagem ou desmontagem. }\end{array}$ & $\begin{array}{l}\text { Gupta (1995), Donaire (1999), } \\
\text { Kleindorfer et al. (2005), Pun } \\
\text { (2006), Baines et al. (2012). }\end{array}$ \\
\hline Eficiência de Produto & $\begin{array}{l}\text { Prioriza durante o desenvolvimento de produtos, } \\
\text { aqueles que possuem menor consumo de energia } \\
\text { durante sua vida útil. Assim como aqueles que } \\
\text { possuem um baixo impacto ambiental durante o seu } \\
\text { uso. }\end{array}$ & $\begin{array}{l}\text { Gupta (1995), Donaire (1999), } \\
\text { Kleindorfer et al. (2005), } \\
\text { Baines et al. (2012). }\end{array}$ \\
\hline $\begin{array}{l}\text { Programas de } \\
\text { Certificação Ambiental e } \\
\text { Auditorias }\end{array}$ & $\begin{array}{l}\text { A empresa possui certificações em programas } \\
\text { específicos para sua indústria, como o concedido } \\
\text { pelo Forest Stewardship Council (FSC) para a } \\
\text { indústria madeireira. Ou participa de um programa de } \\
\text { auditorias ambientais, como a ISO } 14001 .\end{array}$ & $\begin{array}{l}\text { Gupta (1995), Donaire (1999), } \\
\text { Morrow \& Rondinelli (2002), } \\
\text { González-Benito \& González- } \\
\text { Benito (2008). }\end{array}$ \\
\hline $\begin{array}{l}\text { Práticas de Manutenção } \\
\text { e Regulagem }\end{array}$ & $\begin{array}{l}\text { A empresa prioriza a manutenção preventiva de } \\
\text { seus equipamentos, a fim de evitar o desperdício de } \\
\text { matéria-prima. }\end{array}$ & Gupta (1995), Donaire (1999). \\
\hline Processos de Fabricação & $\begin{array}{l}\text { A empresa opta por processos ambientalmente mais } \\
\text { seguros, que reduzem o impacto da organização no } \\
\text { meio ambiente. }\end{array}$ & $\begin{array}{l}\text { Kleindorfer et al. (2005), } \\
\text { Simpson \& Samson (2010), } \\
\text { Baines et al. (2012). }\end{array}$ \\
\hline $\begin{array}{l}\text { Descarte de rejeitos de } \\
\text { produção }\end{array}$ & $\begin{array}{l}\text { Os rejeitos do processo produtivo são enviados à } \\
\text { destinação correta e ambientalmente amigável. Os } \\
\text { descartes podem também serem aproveitados no } \\
\text { próprio processo produtivo da organização (reuso). }\end{array}$ & $\begin{array}{l}\text { Gupta (1995), } \\
\text { Kleindorfer et al. (2005), Pun } \\
\text { (2006), Baines et al. (2012). }\end{array}$ \\
\hline
\end{tabular}

Fonte: Elaborado pelos autores.

Quadro 3. Alguns potenciais conflitos entre operações e gestão ambiental.

\begin{tabular}{|l|l|l|}
\hline \multicolumn{1}{|c|}{ Potencial Conflito } & \multicolumn{1}{c|}{ Características } & \multicolumn{1}{c|}{ Principais Autores } \\
\hline $\begin{array}{l}\text { Aumento do custo de } \\
\text { operações }\end{array}$ & $\begin{array}{l}\text { Mudanças no projeto de novos produtos e no próprio } \\
\text { processo de fabricação sugeridas pela área de meio } \\
\text { ambiente, podem ser custosas e, em alguns casos, } \\
\text { paralisar a produção por períodos de tempo, podendo } \\
\text { impedir que a área de operações cumpra os prazos de } \\
\text { produção e entrega. }\end{array}$ & $\begin{array}{l}\text { Gupta (1995), Baines et al. } \\
(2012) .\end{array}$ \\
\hline $\begin{array}{l}\text { Pouco conhecimento } \\
\text { técnico }\end{array}$ & $\begin{array}{l}\text { Alguns gerentes da área de meio ambiente podem ter } \\
\text { pouco conhecimento técnico sobre o processo produtivo } \\
\text { da empresa, propondo mudanças nos processos e } \\
\text { produtos inviáveis sob o ponto de vista econômico. }\end{array}$ & Rossi \& Barata (2009). \\
\hline Mudança e treinamento & $\begin{array}{l}\text { O fator humano deve ser considerado durante a } \\
\text { mudança dos processos produtivos. Os funcionários } \\
\text { de uma organização podem não se adaptar aos novos } \\
\text { procedimentos exigidos por ações ambientalmente mais } \\
\text { corretas. }\end{array}$ & $\begin{array}{l}\text { Kleindorfer et al. (2005), } \\
\text { Rossi \& Barata (2009), } \\
\text { Baines et al. (2012). }\end{array}$ \\
\hline
\end{tabular}

Fonte: Elaborado pelos autores.

O Quadro 4 traz as principais características das empresas selecionadas em cada um dos critérios de seleção, e, em seguida, é apresentada uma breve descrição de cada organização.

A Empresa A atua no ramo de materiais de construção com a produção de painéis de madeira e pisos laminados na unidade visitada. É uma companhia de grande porte e de capital aberto, com ações negociadas na BM\&F Bovespa. A Empresa
A possui a certificação ISO $14001 \mathrm{em}$ sua planta de produção de painéis e também na área de manejo florestal que abastece a fábrica. Também possui a certificação do Forest Stewardship Council (FSC) em suas áreas de manejo desde 1995. A organização também compõe a carteira de empresas do Índice de Sustentabilidade Empresarial (ISE), bem como expede seu relatório anual de sustentabilidade nos moldes definidos pelo GRI. 
A Empresa B atua majoritariamente no setor químico, mas apresenta ramificações nos setores de transporte, comunicação, cuidados pessoais, material para escritório e eletrônicos. Multinacional de grande porte e de capital aberto, atua no Brasil desde a década de 1940. A Empresa B faz parte do Índice Dow Jones de Sustentabilidade (The Dow Jones Sustainability Index North America). A organização conta com a certificação 14001 para a sede e maior planta industrial. Também expede seu relatório anual de sustentabilidade segundo as diretrizes definidas pelo GRI.

A Empresa $\mathrm{C}$ atua no setor alimentício de bebidas alcoólicas e não alcoólicas. Tradicional no mercado brasileiro, encontra-se em processo de fusão com empresas multinacionais de capital aberto. As unidades da empresa já possuíram a ISO 14001, porém a empresa avaliou que as certificações externas não traziam mais benefícios, visto que o Sistema de Gestão Ambiental (SGA) desenvolvido pela empresa já superaria as exigências da certificação. A empresa não participa do Índice de Sustentabilidade Empresarial, embora tenha suas ações comercializadas na BM\&F Bovespa. A companhia expede seu relatório anual de sustentabilidade nos moldes definidos pelo GRI.

Selecionadas as empresas, iniciou-se o contato com os gestores das áreas de meio ambiente e operações. $\mathrm{O}$ alvo principal dos contatos foram os gerentes ou supervisores das áreas em questão, ou seja, os responsáveis diretos pelas respectivas áreas das empresas.

\subsection{Procedimentos de coleta de dados}

Yin (2010) identificou que entrevistas são uma das fontes de informação mais importantes para o estudo de caso. Dessa forma, foram agendadas entrevistas com os gestores das áreas de operações e meio ambiente das empresas selecionadas. As entrevistas foram realizadas nas próprias empresas e tiveram duração entre uma hora e duas horas e meia. Seguiu-se o modelo de entrevistas semiestruturadas, ou seja, havia um roteiro pré-definido de questões às quais os entrevistados deveriam responder, bem como as respostas eram, em sua maioria, de natureza livre e o entrevistado podia expressar-se com naturalidade sobre o tema abordado.

O roteiro das entrevistas foi validado por um professor externo à pesquisa, para evitar o viés do pesquisador, e conferir maior clareza às perguntas executadas.

Para aumentar a validade interna, buscaram-se coletar informações de outras fontes de dados como documentos apresentados nas empresas, consultas aos sites das organizações, observações diretas do pesquisador, almejando reduzir o viés da percepção deste sobre o objeto de estudo e aumentando a confiabilidade da pesquisa, bem como seu caráter científico (Claver et al., 2007; Yin, 2010).

Com a replicação destes procedimentos para todas as empresas, buscou-se garantir a validade externa da pesquisa dentro dos casos analisados. Para aumentar a confiabilidade, solicitou-se a todos os entrevistados a gravação do áudio das entrevistas para posterior transcrição.

O Quadro 5 apresenta as informações e as fontes consultadas em cada uma das empresas selecionadas.

$\mathrm{Na}$ empresa A, foram entrevistados o supervisor de processo e produção, que possui 16 anos de experiência no setor, e a supervisora de meio ambiente, a qual atua há 10 anos na área. A pedido da empresa, essa entrevista não pôde ser gravada, pois não havia autorização prévia. Durante a entrevista, foram exibidos vídeos institucionais e apresentações de slides, e documentos internos. Depois da entrevista, seguiu-se uma visita à linha de produção da empresa, na qual pôde-se corroborar algumas informações

Quadro 4. Informações sobre as empresas pesquisadas.

\begin{tabular}{|l|l|l|l|}
\hline & \multicolumn{1}{|c|}{ Empresa A } & \multicolumn{1}{c|}{ Empresa B } & \multicolumn{1}{c|}{ Empresa C } \\
\hline Caracterização & $\begin{array}{l}\text { Empresa nacional atuante } \\
\text { no setor de materiais de } \\
\text { construção. }\end{array}$ & $\begin{array}{l}\text { Empresa multinacional no } \\
\text { ramo químico e de indústria } \\
\text { de transformação. }\end{array}$ & $\begin{array}{l}\text { Empresa nacional em } \\
\text { processo de fusão, tradicional } \\
\text { produtora de bebidas no } \\
\text { mercado brasileiro. }\end{array}$ \\
\hline Porte & Grande & Grande & Grande \\
\hline Capital & Aberto & $\begin{array}{l}\text { Aberto nos EUA e limitado } \\
\text { no Brasil }\end{array}$ & Aberto \\
\hline Fatores de escolha & $\begin{array}{l}\text { Possui ISO 14001; } \\
\text { Certificação FSC; } \\
\text { Relatório de sustentabilidade } \\
\text { nos moldes do GRI. }\end{array}$ & $\begin{array}{l}\text { Possui ISO 14001; } \\
\text { Não compõe o ISE, porém } \\
\text { compõe o Índice Dow Jones } \\
\text { de Sustentabilidade; } \\
\text { Relatório de sustentabilidade } \\
\text { nos moldes do GRI. }\end{array}$ & $\begin{array}{l}\text { Não possui ISO 14001, mas } \\
\text { possui sistema de gestão } \\
\text { ambiental equivalente; } \\
\text { Não compõe o ISE; } \\
\text { Relatório de sustentabilidade } \\
\text { nos moldes do GRI. }\end{array}$ \\
\hline
\end{tabular}

Fonte: Elaborado pelos autores. 
Quadro 5. Informações e fontes consultadas.

\begin{tabular}{|c|c|c|c|}
\hline & Entrevista & Dados Secundários & Observação Direta \\
\hline Empresa A & $\begin{array}{l}\text { Foram entrevistados o } \\
\text { supervisor de processo e } \\
\text { produção, com } 16 \text { anos de } \\
\text { experiência, e a supervisora de } \\
\text { meio ambiente, com } 10 \text { anos de } \\
\text { experiência na área. } \\
\text { A entrevista não pôde ser } \\
\text { gravada. }\end{array}$ & $\begin{array}{l}\text { Foram consultados documentos } \\
\text { e apresentações de slides } \\
\text { durante a entrevista. } \\
\text { Foi visitado o site da empresa e } \\
\text { examinado seu relatório anual e } \\
\text { de sustentabilidade. }\end{array}$ & $\begin{array}{l}\text { Foi visitada a linha de } \\
\text { produção da empresa e a área } \\
\text { administrativa. }\end{array}$ \\
\hline Empresa B & $\begin{array}{l}\text { Foram entrevistados o gerente } \\
\text { de Environment Health and } \\
\text { Security (EHS), com mais } \\
\text { de } 27 \text { anos de experiência, } \\
\text { e uma especialista em } \\
\text { Sustentabilidade, com } 10 \text { anos } \\
\text { de experiência. } \\
\text { A entrevista pôde ser gravada. }\end{array}$ & $\begin{array}{l}\text { Foram consultados documentos } \\
\text { durante a entrevista. } \\
\text { Foi visitado o site da empresa e } \\
\text { examinado seu relatório anual e } \\
\text { de sustentabilidade. }\end{array}$ & $\begin{array}{l}\text { Foi verificada a área } \\
\text { administrativa da empresa. }\end{array}$ \\
\hline Empresa C & $\begin{array}{l}\text { Foi entrevistado o gerente de } \\
\text { meio ambiente, com } 10 \text { anos de } \\
\text { experiência na área. } \\
\text { A entrevista pôde ser gravada. }\end{array}$ & $\begin{array}{l}\text { Foi visitado o site da empresa e } \\
\text { examinado seu relatório anual e } \\
\text { de sustentabilidade. }\end{array}$ & $\begin{array}{l}\text { Não pôde ser verificada nem a } \\
\text { linha de produção nem a área } \\
\text { administrativa. }\end{array}$ \\
\hline
\end{tabular}

Fonte: Elaborado pelos autores.

coletadas e novos dados foram adicionados. Por fim, consultou-se o site da companhia, que possui uma área destinada à sustentabilidade das ações e produtos da empresa. No mesmo site, consultou-se o relatório anual de sustentabilidade, principal documento de comunicação das ações realizadas pela empresa para seus stakeholders.

$\mathrm{Na}$ empresa B, foram entrevistados o gerente da área de Environment, Health and Security (EHS), que atua na empresa há mais de 27 anos, e uma especialista em Sustentabilidade e Meio Ambiente, com 10 anos de experiência na empresa. Com a autorização dos entrevistados, a conversa pôde ser gravada, mas, após a entrevista, não foi possível visitar a linha de produção da empresa, pois a entrada na linha é vetada a não funcionários. Porém, foi possível visitar a área administrativa e verificar os postos de trabalho das equipes das áreas. Durante a entrevista, foram mostrados documentos e também foi visitado o site da companhia. Consultou-se também o relatório anual de sustentabilidade.

Para análise da empresa $\mathrm{C}$, foi entrevistado o gerente de meio ambiente, que atua há 10 anos na empresa, sendo, grande parte desse tempo, na área de meio ambiente da companhia. A entrevista foi gravada com autorização da empresa e, após esta, não se pode visitar a linha de produção. É importante ressaltar que a empresa foi visitada a poucas semanas do carnaval, pico de produção para a indústria de bebidas alcoólicas, o que dificultou o acesso à linha de produção da empresa. Foram consultados o site e o relatório anual de sustentabilidade.

\subsection{Procedimentos de análise de dados}

Os dados coletados em cada uma das empresas foram compilados em três relatos de casos. Os relatos continham a transcrição integral do áudio das entrevistas nas Empresas B e C; para a Empresa A, foi feito um resumo com os principais pontos da entrevista. Também faziam parte dos relatos os dados secundários encontrados, contidos nos sites das empresas, nos documentos apresentados, nas apresentações mostradas e nos dados presentes nos relatórios anuais e de sustentabilidade das companhias. Foram adicionadas também as observações diretas feitas pelo pesquisador, sejam as feitas durante a visita à linha de produção da Empresa $\mathrm{A}$, como também as feitas nas visitas às áreas administrativas da Empresa A e Empresa B.

A construção dos relatos compôs a fase de análise interna dos casos, como propõe Eisenhardt (1989). A mesma autora afirma que esta primeira análise é puramente descritiva, e auxilia o pesquisador que apresenta um grande volume de dados.

Depois da análise interna dos casos, foi feita uma análise cross case, que consiste na busca por padrões, similaridades e divergências entre os casos estudados. Uma das táticas identificadas por Eisenhardt (1989) é a de selecionar dimensões de análise, as quais podem ser identificadas dentro da literatura ou atribuídas pelos pesquisados e, dentro dessas regiões, elaborar uma análise em busca de similaridades e diferenças.

As dimensões escolhidas para a análise cross case foram os subsistemas da estrutura organizacional observados por Vasconcellos \& Hemsley (2002): autoridade, atividade e comunicação. 


\section{Resultados}

\subsection{Autoridade}

A autoridade refere-se à distribuição de liderança e à hierarquia da empresa. Esse aspecto é importante para localizar as duas áreas dentro do organograma da empresa e avaliar a cadeia de comando à qual as áreas estão submetidas, bem como as estruturas das áreas.

Todas as empresas pesquisadas apresentam estrutura hierárquica verticalizada, com cargos bem definidos e linha de comando pré-estabelecida.

$\mathrm{Na}$ Empresa $\mathrm{A}$, a área de meio ambiente tornou-se independente da área de qualidade no início do ano de 2013, embora a área estivesse em atuação desde 2001. Os departamentos de meio ambiente e produção possuem o mesmo nível hierárquico na estrutura da empresa, sendo que ambos respondem para o mesmo gerente da fábrica. Internamente, os departamentos de meio ambiente e de produção e operações apresentam os mesmos cargos administrativos, o que denota que a estrutura hierárquica é similar entre as duas áreas. Também na Empresa A, existe um comitê de sustentabilidade ligado diretamente ao conselho administrativo. E a presidência da companhia apresenta uma área de sustentabilidade corporativa, cuja função é estabelecer políticas ambientais para a organização como um todo.

$\mathrm{Na}$ Empresa B, a área de meio ambiente pertence ao departamento de meio ambiente, saúde e segurança (Environment, Health and Security - EHS), a qual é independente dos demais departamentos, assim como o departamento de produção. Ambos os departamentos respondem para o mesmo superior. Também foi afirmado pelos entrevistados que a estrutura de cargos é a mesma para ambas as áreas, tornando os departamentos parelhos e a cadeia de autoridade constante dentro da empresa. O departamento de meio ambiente, saúde e segurança da Empresa B é o mais antigo dentre as empresas pesquisadas, datando do ano de 1951, quando foi criado pela matriz nos Estados Unidos, sendo progressivamente incorporado às filiais da organização.

A Empresa $\mathrm{C}$ foi uma das pioneiras em seu setor a desenvolver políticas e uma área dedicada a assuntos relacionados ao meio ambiente no ano de 1992. Sendo assim, o departamento de meio ambiente é independe dos demais, bem como o departamento de operações. Também foi constatado que os departamentos apresentam a mesma estrutura de cargos, sendo que o gerente de meio ambiente de cada unidade responde para uma diretoria de meio ambiente, localizada na matriz da empresa. O mesmo ocorre para o gerente de operações, porém este responde para uma diretoria de operações. A diretoria de meio ambiente da Empresa $\mathrm{C}$ é composta por especialistas nas áreas de águas, efluentes, projetos e subprodutos.

\subsection{Atividade e comunicação (Pontos de Contato)}

$\mathrm{Na}$ aproximação entre as áreas, surgem os pontos de contato, as atividades realizadas em conjunto pelos departamentos da empresa. A realização dessas atividades somente torna-se possível pela comunicação entre os membros dos departamentos. Os pontos de contato e as formas mais comuns de comunicação entre as áreas foram levantados pela literatura. O Quadro 6 traz as informações de como os pontos de contato estão sendo explorados pelas empresas pesquisadas.

Os pontos pesquisados foram agrupados em três categorias: os que se referem ao design dos produtos oferecidos pela empresa, os que versam sobre os processos fabris da organização, e aqueles que citam os descartes dos rejeitos de produção.

\section{- Aspectos sobre design de produtos e embalagens}

O processo de desenvolvimento de novos produtos conta com a participação de várias áreas nas Empresas A e B. Essa interação ocorre por meio do preenchimento de um checklist, cujos itens dizem sobre a adoção de técnicas de design mais ambientalmente amigáveis e sobre a eficiência dos produtos; ou seja, buscar o menor consumo de recursos durante o uso do produto. Durante a elaboração desse documento, os departamentos de meio ambiente e operações, assim como outros envolvidos, discutem os aspectos do projeto, implementando boas práticas de desenvolvimento ecológico de produto.

Esse documento estende-se até a embalagem dos produtos, almejando a racionalização quanto ao número de embalagens e o uso de materiais alternativos na Empresa A. Quanto à Empresa B, existe uma área exclusiva de desenvolvimento de embalagens, a qual possui autonomia para desenvolver e propor soluções.

A readequação de produtos já existentes é um ponto de diferença. Enquanto que a Empresa A aplica o mesmo checklist usado para o desenvolvimento de produtos novos, a Empresa $\mathrm{B}$ não apresenta procedimento específico para esta situação, sendo os funcionários, de todas as áreas, incentivados a buscar e propor melhorias em diversos pontos da empresa, como parte de um programa de reconhecimento interno.

Como a Empresa $\mathrm{C}$ atua no ramo alimentício de produção de bebidas, as questões sobre design e eficiência de produto não se aplicam. Focou-se então na questão sobre o design de embalagens. O processo de projeto de embalagens é realizado pela matriz da empresa, sendo que as filiais apenas recebem o material acabado. Solicitações de mudança rumo à sustentabilidade, geralmente partem dos diretores (meio ambiente, marketing), e então são encaminhadas para a equipe de desenvolvimento. Essa estratégia foi adotada para a elaboração de uma embalagem composta por $100 \%$ de material reciclado, 
a qual serviu de base para uma ampla campanha de marketing veiculada pela empresa.

\section{- Aspectos sobre processo de fabricação}

Para a aquisição e manutenção das certificações obtidas, todas as empresas requerem que suas áreas atuem em conjunto. Nas Empresas A e C, a interação entre as áreas de meio ambiente e operações ocorre por meio de treinamentos destinados aos funcionários e da realização de auditorias. Na Empresa B, é a área de qualidade que capitaneia o processo de manutenção das certificações, identificando os pontos de melhoria e os encaminhando para as áreas competentes, assim as áreas de meio ambiente e operações não necessitam

Quadro 6. Como os pontos de contato são explorados nas empresas pesquisadas.

\begin{tabular}{|c|c|c|c|}
\hline Pontos de contato & Empresa A & Empresa B & Empresa C \\
\hline $\begin{array}{l}\text { Relacionamento durante o } \\
\text { desenvolvimento de novos } \\
\text { produtos }\end{array}$ & $\begin{array}{l}\text { Preenchimento de um } \\
\text { check list em conjunto com } \\
\text { outras áreas. Contém itens } \\
\text { relacionados a ecodesign, } \\
\text { embalagens e eficiência do } \\
\text { produto. }\end{array}$ & $\begin{array}{l}\text { Preenchimento de um } \\
\text { check list } \text { em conjunto com } \\
\text { outras áreas. Contém itens } \\
\text { relacionados a ecodesign, } \\
\text { embalagens e eficiência do } \\
\text { produto. }\end{array}$ & $\begin{array}{l}\text { Não se aplica à empresa, } \\
\text { pelo tipo de produto } \\
\text { oferecido. }\end{array}$ \\
\hline $\begin{array}{l}\text { Relacionamento durante o } \\
\text { desenvolvimento de novas } \\
\text { embalagens }\end{array}$ & $\begin{array}{l}\text { Preenchimento de um } \\
\text { check list em conjunto com } \\
\text { outras áreas. Contém itens } \\
\text { relacionados a ecodesign, } \\
\text { embalagens e eficiência do } \\
\text { produto. }\end{array}$ & $\begin{array}{l}\text { Existe uma área específica } \\
\text { para o desenvolvimento } \\
\text { de embalagens, que tem } \\
\text { autonomia para buscar } \\
\text { soluções. }\end{array}$ & $\begin{array}{l}\text { Não se aplica à empresa, } \\
\text { pelo tipo de produto } \\
\text { oferecido. }\end{array}$ \\
\hline $\begin{array}{l}\text { Relacionamento para } \\
\text { aumentar a eficiência do } \\
\text { produto }\end{array}$ & $\begin{array}{l}\text { Preenchimento de um } \\
\text { check list em conjunto com } \\
\text { outras áreas. Contém itens } \\
\text { relacionados a ecodesign, } \\
\text { embalagens e eficiência do } \\
\text { produto. }\end{array}$ & $\begin{array}{l}\text { Incentivo aos funcionários } \\
\text { para trazerem soluções } \\
\text { de melhora dos produtos } \\
\text { por meio do programa de } \\
\text { reconhecimento interno. }\end{array}$ & $\begin{array}{l}\text { A decisão parte dos } \\
\text { diretores (meio ambiente, } \\
\text { marketing) e é enviada } \\
\text { para o desenvolvimento de } \\
\text { embalagens. }\end{array}$ \\
\hline $\begin{array}{l}\text { Trabalho em conjunto na } \\
\text { obtenção e manutenção de } \\
\text { certificações }\end{array}$ & $\begin{array}{l}\text { Realizado por meio de } \\
\text { treinamentos e auditorias } \\
\text { internas. }\end{array}$ & $\begin{array}{l}\text { Intermédio da área de } \\
\text { qualidade, que identifica } \\
\text { os pontos de melhoria e } \\
\text { encaminha para as áreas } \\
\text { competentes. }\end{array}$ & $\begin{array}{l}\text { Realizado por meio de } \\
\text { treinamentos e auditorias } \\
\text { internas. }\end{array}$ \\
\hline Auditorias ambi & $\begin{array}{l}\text { Internas, com auditores } \\
\text { treinados em todas as áreas } \\
\text { sob a supervisão de um } \\
\text { auditor chefe da área de } \\
\text { meio ambiente. }\end{array}$ & $\begin{array}{l}\text { Corporativas, com } \\
\text { auditores vindos da } \\
\text { matriz da empresa, com o } \\
\text { acompanhamento da área } \\
\text { de meio ambiente. }\end{array}$ & $\begin{array}{l}\text { Internas e Corporativas, } \\
\text { também realiza auditorias } \\
\text { nas empresas parceiras. }\end{array}$ \\
\hline $\begin{array}{l}\text { Participação de meio } \\
\text { ambiente no programa de } \\
\text { manutenção preventiva }\end{array}$ & $\begin{array}{l}\text { Possui participação } \\
\text { segundo procedimento } \\
\text { documentado. }\end{array}$ & Não possui $p$ & $\begin{array}{l}\text { Possui participação por meio } \\
\text { de equipe multidisciplinar } \\
\text { e acompanhamento de } \\
\text { relatórios. }\end{array}$ \\
\hline $\begin{array}{l}\text { Trabalho em conjunto } \\
\text { durante a modificação do } \\
\text { processo de fabricação }\end{array}$ & $\begin{array}{l}\text { Aplicação de um check } \\
\text { list similar ao aplicado } \\
\text { para o desenvolvimento de } \\
\text { produto. }\end{array}$ & $\begin{array}{l}\text { Modificações realizadas } \\
\text { devem estar acompanhadas } \\
\text { de um documento } \\
\text { específico. }\end{array}$ & $\begin{array}{l}\text { É a área de meio ambiente } \\
\text { que libera a modificação do } \\
\text { processo. Sem a liberação, } \\
\text { a modificação não pode ser } \\
\text { implementada. }\end{array}$ \\
\hline $\begin{array}{l}\text { Participação de meio } \\
\text { ambiente na discussão } \\
\text { sobre o descarte de rejeitos }\end{array}$ & $\begin{array}{l}\text { Realizada durante o projeto } \\
\text { de novo produto. }\end{array}$ & $\begin{array}{l}\text { Realizada durante o projeto } \\
\text { de novo produto. }\end{array}$ & $\begin{array}{l}\text { Meio ambiente é a } \\
\text { responsável pela destinação } \\
\text { dos rejeitos. }\end{array}$ \\
\hline $\begin{array}{l}\text { Acompanhamento de meio } \\
\text { ambiente do processo de } \\
\text { destinação dos rejeitos }\end{array}$ & $\begin{array}{l}\text { Agente fiscalizador, } \\
\text { acompanha os relatórios e } \\
\text { envia técnicos até o local. }\end{array}$ & $\begin{array}{l}\text { Área que gerencia os } \\
\text { rejeitos é subordinada à } \\
\text { área de meio ambiente. }\end{array}$ & $\begin{array}{l}\text { Meio ambiente é a } \\
\text { responsável pela destinação } \\
\text { dos rejeitos. }\end{array}$ \\
\hline $\begin{array}{l}\text { Incentivo da área de meio } \\
\text { ambiente ao reuso dos } \\
\text { rejeitos de produção }\end{array}$ & $\begin{array}{l}\text { Funcionários são } \\
\text { incentivados a trazer novas } \\
\text { ideias de reuso. }\end{array}$ & $\begin{array}{l}\text { Incentivo por meio } \\
\text { do programa de } \\
\text { reconhecimento interno. }\end{array}$ & $\begin{array}{l}\text { Pontos de reuso já } \\
\text { mapeados, a área vistoria } \\
\text { para que estejam sendo } \\
\text { cumpridos. }\end{array}$ \\
\hline
\end{tabular}

Fonte: Elaborado pelos autores. 
trabalhar em conjunto, obrigatoriamente, pois contam com o intermédio da área de qualidade.

Todas as empresas pesquisadas realizam auditorias com a participação, direta ou indireta da área de meio ambiente. Nas Empresas A e C a participação é direta. $\mathrm{Na}$ Empresa A, são realizadas auditorias internas, supervisionadas por um auditor chefe da área de meio ambiente e funcionários treinados como auditores internos. A Empresa $\mathrm{C}$ realiza auditorias internas, bem como também promove inspeções nas plantas industriais das organizações parceiras. Essa ação é realizada em toda a cadeia produtiva. Já a Empresa $\mathrm{B}$ realiza suas auditorias por meio de responsáveis vindos da matriz americana ou outros auditores corporativos, contando com o acompanhamento do departamento de meio ambiente, saúde e segurança, seguindo procedimento preestabelecido. Por fim, a Empresa $\mathrm{C}$ também realiza auditorias promovidas pelo corporativo, que ocorrem semestralmente.

Nas Empresas A e C, o programa de manutenção dos equipamentos conta com a participação da área de meio ambiente, por meio da execução de procedimentos específicos, quando necessário, e do acompanhamento dos relatórios de manutenção. $\mathrm{O}$ mesmo não ocorre na Empresa B, na qual o programa de manutenção não possui interação com a área de meio ambiente.

Durante a modificação do processo de fabricação, todas as empresas pesquisadas apresentaram interações entre as áreas de meio ambiente e operações. Na Empresa $\mathrm{A}$, há a aplicação de um checklist, similar ao aplicado durante a criação de novos produtos, em que aspectos de meio ambiente são avaliados. Na Empresa B, as modificações realizadas devem estar acompanhadas de um documento específico, o qual apresenta itens sobre segurança e meio ambiente. Na Empresa C, nenhuma modificação pode ser realizada no processo sem a validação prévia da área de meio ambiente.

\section{- Aspectos sobre rejeitos de produção}

Em todas as empresas consultadas, a área de meio ambiente participa da discussão sobre a destinação mais adequada de rejeitos de produção. Nas Empresas A e B, essa avaliação é feita durante o projeto do novo produto. Na Empresa $\mathrm{C}$, a área de meio ambiente é a responsável pelos rejeitos, alocando-os da forma mais sustentável possível.

Sobre o acompanhamento da destinação dos descartes, todas as empresas afirmaram realizar essa atividade. Na Empresa A, meio ambiente age como agente fiscalizador, enviando técnicos até o local de descarte e acompanhando relatórios. Nas Empresas B e C, a área de meio ambiente é parcial e inteiramente responsável pelo descarte de rejeitos, respectivamente. $\mathrm{Na}$ Empresa B, a área que gerencia os rejeitos é subordinada à área de meio ambiente, e na Empresa $\mathrm{C}$, é a própria área de meio ambiente que opera o recebimento e tratamento dos rejeitos.
Por fim, em todas as empresas, o reuso dos rejeitos, quando possível, é incentivado pela organização como um todo. Nas Empresas A e B, os funcionários são estimulados a propor e implementar soluções que possam reduzir a emissão de poluentes, reduzir o consumo, aumentar o reuso, entre outros. A Empresa $\mathrm{C}$ já possui os pontos de reuso mapeados, cabendo à área de meio ambiente fiscalizar se essas atividades estão sendo cumpridas adequadamente.

Foram levantadas também formas de comunicação entre departamentos. O nível de relacionamento entre departamentos está ligado com a adoção de meios mais ou menos efetivos de comunicação organizacional.

Todas as empresas pesquisadas realizam reuniões formais nas quais participam as áreas de meio ambiente e operações. As reuniões são compartilhadas com outras áreas da organização, nas quais são discutidos aspectos gerais da companhia, como metas produtivas, o desempenho da empresa, índices de treinamento, entre outros. A Empresa $\mathrm{C}$ foi a única que relatou possuir uma reunião especifica da área de meio ambiente com a área de operações, com pauta contendo itens obrigatórios de meio ambiente.

Todas as empresas relataram possuir fluxo de troca de documentos entre as áreas pesquisadas. Esse fluxo de troca ocorre por meio dos sistemas de gestão integrada de cada uma das empresas, nos quais ficam arquivados relatórios, atas, memorandos, os quais estão disponíveis para consulta para todas as áreas da organização.

Nas Empresas A e C, há a elaboração de metas conjuntas entre as áreas de meio ambiente e operações. Na Empresa A, essas metas são discutidas conjuntamente com a direção da organização; na Empresa C, essas metas são mais rigorosas que as indicadas pela matriz da companhia, ou seja, na Empresa C, as áreas estudadas criam metas mais arrojadas de redução do que as fixadas pela direção. Já para a Empresa B, não há a discussão de metas conjuntas, mas existe uma intenção de isto ser realizado no futuro.

Todas as empresas pesquisadas relataram que compartilham alguns objetivos entre as áreas de meio ambiente e operações por meio de uma política conjunta. Na Empresa B, esses objetivos são os colocados pela matriz americana.

Sobre o compartilhamento de recursos, as empresas pesquisadas afirmam compartilhar totalmente a informação entre as áreas. Com exceção da Empresa $\mathrm{C}$, na qual o entrevistado relatou que algumas atividades muito específicas das áreas não têm as informações compartilhadas, por estar fora da rotina da área solicitante.

Todas as empresas relataram possuir equipes multidisciplinares formadas com membros de ambas as áreas pesquisadas. Existe a atividade por pequenos grupos (APG), que debate temas quando necessário na Empresa A. A Empresa B possui 
equipes multidisciplinares destinadas a projetos, assim as equipes são desfeitas quando do término do projeto. A Empresa $\mathrm{C}$ foi a única que apresentou um grupo multidisciplinar permanente formado com membros das áreas pesquisadas. A companhia possui uma comissão interna de meio ambiente, da qual participam todas as áreas da empresa. A Empresa $\mathrm{C}$ também possui uma equipe multidisciplinar voltada para a manutenção dos equipamentos.

A alta administração incentiva o relacionamento entre as áreas de meio ambiente e operações em todas as empresas. Na Empresa B há o incentivo por meio do programa de redução de poluição, em que os funcionários são estimulados a trazer soluções inovadoras para reduzir os poluentes. Nas Empresas A e C o incentivo ocorre por meio da disseminação da cultura ambiental dentro dos vários níveis e departamentos das empresas; na Empresa A, isso se evidencia pelos treinamentos fornecidos, incentivos à criação de um corpo de auditores internos; e, na Empresa C, pela política ambiental unificada, seguida em todas as unidades da empresa.

\subsection{Conflitos}

O relacionamento entre os departamentos das empresas pode levar à diferença de ideias e conflitos entre os membros. Não foram observados conflitos decorrentes desse relacionamento nos casos estudados, como é apresentado a seguir.

Os entrevistados nas três empresas pesquisadas afirmaram não presenciar conflitos durante o relacionamento entre as áreas de meio ambiente e operações, tampouco evidenciaram divergências. Embora, na Empresa B, segundo os entrevistados, a área de meio ambiente parece ser vista como punitiva, como se dificultasse os processos das outras áreas.

Todas as empresas pesquisadas assumem as atividades realizadas pela área de meio ambiente como inerentes ao negócio, mesmo com o possível aumento de custos. Para a Empresa B, o aumento de custos é gerado por uma demanda de investimento não prevista, para correções, mudanças de última hora, falhas de planejamento. Para a Empresa C, as ações de meio ambiente geram custos, mas são necessárias, e se algum problema de meio ambiente necessita de mais recursos, e estes não estão imediatamente disponíveis, a gerência da unidade discute e faz uma realocação de recursos.

A necessidade de treinamentos dos funcionários também não é vista como um potencial conflito, mas como uma oportunidade de melhoria. As Empresas $\mathrm{A}$ e $\mathrm{C}$ se valem dos treinamentos para promover a política e a cultura ambiental das companhias para os funcionários. Na Empresa B, os treinamentos são vistos como uma constante e são incentivados pela administração da companhia.
As três áreas de meio ambiente consultadas relataram conhecer bem os processos e as necessidades da área de operações. Na Empresa A, esse conhecimento é visto como fundamental e adquirido no dia a dia. Já a Empresa B acredita que o perfil dos contratados na área de meio ambiente, todos graduados em engenharia, facilita o entendimento das atividades da área de processos. A Empresa $\mathrm{C}$ executa treinamentos com todos os funcionários, mesmo os administrativos, sobre os processos de fabricação e envase dos produtos. Desse modo, acreditam que todos os funcionários compreendem as atividades da área de operações.

\section{Discussões e considerações finais}

As empresas estudadas demonstraram ser ambientalmente proativas e maduras, uma vez que a área de meio ambiente já existe nessas empresas há pelo menos 10 anos. Além do mais, as empresas possuem práticas ambientais de destaque como Sistema de Gestão Ambiental/LSO 14001, selo ambiental (FSC) e relatório de sustentabilidade (GRI). Este aspecto é importante de ser ressaltado, pois, em função disso, é possível compreender por que as empresas pesquisadas exploram diversos pontos de contato entre as áreas de operações e meio ambiente e não possuem conflitos que mereçam destaque entre essas áreas. Jabbour \& Santos (2006) já haviam apontado a importância da proatividade ambiental para compreender o papel de meio ambiente de maior ou menor responsabilidade na organização.

Nas três empresas estudadas, em função do organograma da empresa e dos relatos dos entrevistados, constata-se que a área de meio ambiente possui autonomia suficiente para executar as suas funções e suportar também atividades de outras áreas, como a de operações. Nesse sentido, a lógica de funcionamento das áreas de meio ambiente segue a proposta de integração matricial de Corazza (2003), o que mais uma vez reforça o aspecto de proatividade ambiental das empresas estudadas.

Todos os pontos de contato elencados na literatura são explorados de uma forma geral pelas empresas pesquisadas. Dentre todas as atividades de contato, pode-se dar um destaque maior à atividade de "modificação do processo de fabricação", pois nas três empresas há procedimentos formais em que a participação de meio ambiente é fundamental, a ponto de, na Empresa $\mathrm{C}$, se a área de meio ambiente não autorizar a modificação, esta não é realizada. A realidade das empresas estudadas vai ao encontro do anseio de Baines et al. (2012), que afirmam que a função operações necessita ampliar seu entendimento sobre as práticas de produção mais ambientalmente amigáveis.

$\mathrm{O}$ relacionamento mantido entre as áreas de operações e meio ambiente nas empresas estudadas permite que a comunicação entre as áreas seja muito 


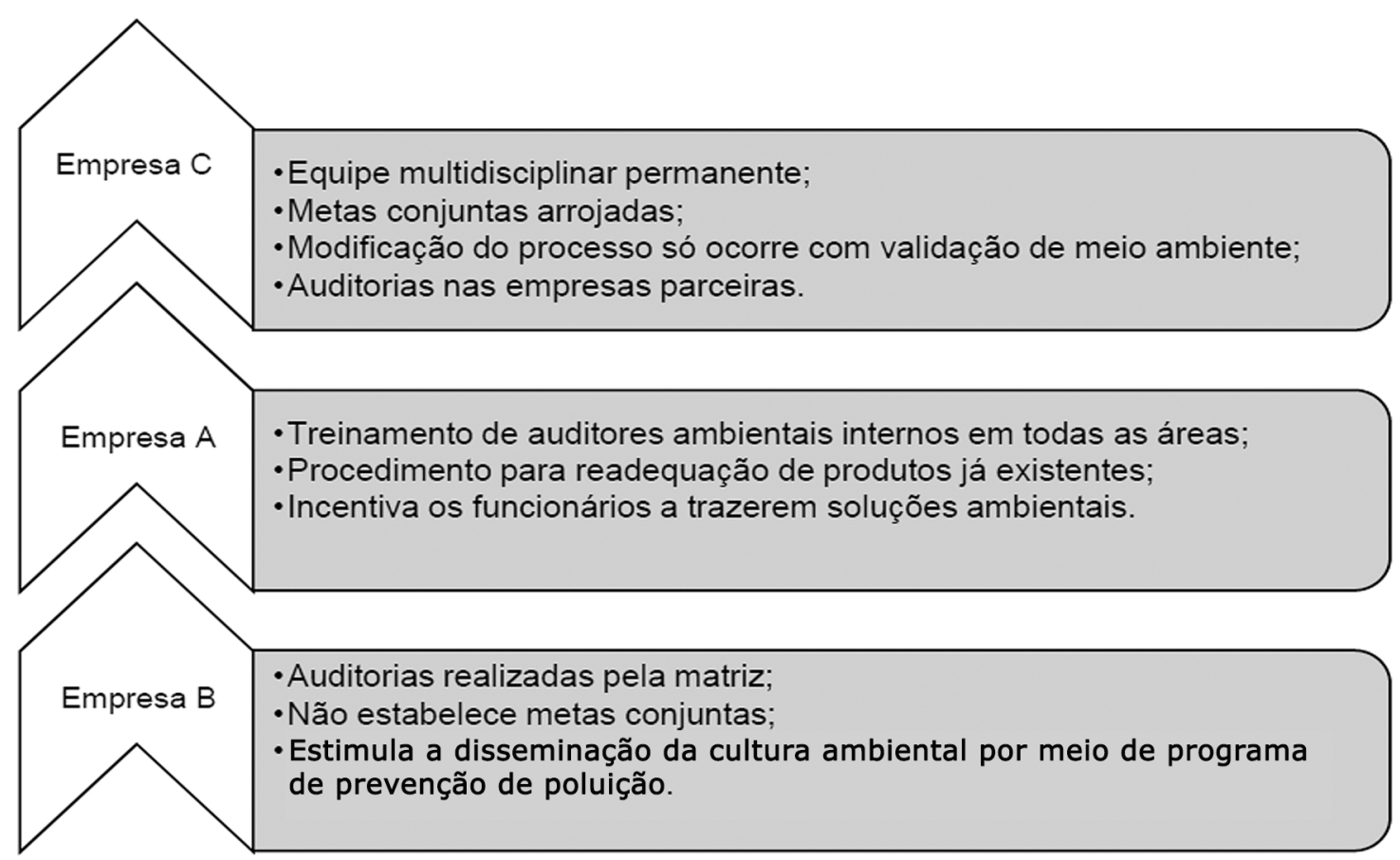

Figura 2. Classificação das empresas pesquisadas quanto ao nível de relacionamento. Fonte: Elaborado pelos autores.

presente e facilitada. Em geral, segundo a classificação de Kahn (2001), as empresas estão entre a colaboração e a integração interfuncional entre operações e meio ambiente. Essa classificação acompanha a percepção dos entrevistados, os quais foram questionados sobre como avaliavam o nível de relacionamento entre as áreas estudadas em uma escala de baixo, médio e alto. Os entrevistados da Empresa A escolheram o nível alto, enquanto que, os da Empresa B escolheram o nível médio. $\mathrm{O}$ entrevistado da Empresa $\mathrm{C}$ fez questão de reforçar que identificava um nível muito alto de relacionamento.

A ausência de conflitos que mereçam destaque por parte dos entrevistados pode ser justificada em função da maturidade ambiental das empresas estudadas e da forma como as áreas de operações e meio ambiente se relacionam, podendo-se inferir que esses foram sendo neutralizados ao longo do tempo.

Considerando as três dimensões analisadas, autoridade, atividades e comunicação, posicionaram-se as empresas em uma escala a fim de destacar os seus principais pontos de mérito. Por esse parâmetro, a Empresa $C$ é a primeira colocada, seguida pelas empresas A e B. A Figura 2 ilustra a classificação das empresas.

Segundo Galeazzo et al. (2014), a literatura sobre a interface entre as áreas de produção e meio ambiente foca mais o papel da relação do que como esta relação é implementada, portanto, esta pesquisa contribui com a literatura ao trazer exemplos de como empresas ambientalmente proativas têm explorado os pontos de contato entre essas áreas. O Quadro 6 e as demais informações apontadas na Seção 4 sobre as dimensões de autoridade, atividade e comunicação, ilustram diferentes formas de viabilizar a relação entre operações e meio ambiente, sendo, portanto, fonte de benchmarking para empresas que ainda presenciam muitos conflitos interfuncionais entre essas áreas.

Sugere-se, como pesquisas futuras, ampliar o número de observações sobre esta temática, mas tentando considerar empresas em diferentes estágios de maturidade ambiental, a fim de poder avaliar as diferenças que este aspecto gera nas análises dos pontos de contato e nos conflitos interfuncionais. Também pode ser objeto de estudo a influência da estrutura informal da organização sobre os pontos de contato e os conflitos pesquisados.

\section{Agradecimentos}

Os autores gostariam de agradecer à Fundação de Amparo à Pesquisa do Estado de São Paulo (FAPESP) o suporte fornecido para a realização desta pesquisa por meio do Processo FAPESP 2013/07619-6.

\section{Referências}

Baines, T., Brown, S., Benedettini, O., \& Ball, P. (2012). Examining green production and its role within the competitive strategy of manufacturers. Journal of Industrial Engineering and Management, 5(1), 53-87. http://dx.doi.org/10.3926/jiem.405. 
Claver, E., López, M. D., Molina, J. F., \& Tarí, J. J. (2007). Environmental management and firm performance: a case study. Journal of Environmental Management, 84(4), 606-619. http://dx.doi.org/10.1016/j.jenvman.2006.09.012.

Corazza, R. I. (2003). Gestão ambiental e mudanças da estrutura organizacional. RAE Eletrônica, 2(2), 1-23. http://dx.doi.org/10.1590/S1676-56482003000200006.

Corbett, C., \& Klassen, R. (2006). Extending the horizons: environmental excellence as key to improving operations. Manufacturing \& Service Operations Management, 8(1), 5-22. http://dx.doi.org/10.1287/msom.1060.0095.

Daft, R. L. (2010). Organization theory and design (10. ed.). Mason: South-Western Cengage Learning.

Despeisse, M., Ball, P. D., Evans, S., \& Levers, A. (2012). Industrial ecology at factory level - a conceptual model. Journal of Cleaner Production, 31, 30-39. http://dx.doi. org/10.1016/j.jclepro.2012.02.027.

Donaire, D. (1999). Gestão ambiental na empresa (2. ed.). São Paulo: Atlas.

Durham, D. R. (2002). Environmentally benign manufacturing: current practice and future trends. Journal of Operations Management, 54(5), 34-37.

Eisenhardt, K. M. (1989). Building theories from case study research. Academy of Management Review, 14(4), 532-550.

Fryxell, G. E., \& Vryza, M. (1999). Managing environmental issues across multiple functions: an empirical study of corporate environmental departments and functional co-ordination. Journal of Environmental Management, 55(1), 39-56. http://dx.doi.org/10.1006/jema.1998.0241.

Galeazzo, A., Furlan, A., \& Vinelli, A. (2014). Understanding environmental-operations integration: the case of pollution prevention projects. International Journal of Production Economics, 153, 149-160. http://dx.doi. org/10.1016/j.ijpe.2014.02.015.

Global Reporting Initiative - GRI. (2015). About GRI. Recuperado em 21 de setembro de 2015, de https:// www.globalreporting.org/Information/about-gri/Pages/ default.aspx.

González-Benito, J., \& González-Benito, Ó. (2008). Operations management practices linked to the adoption of ISO 14001: an empirical analysis of Spanish manufacturers. International Journal of Production Economics, 113(1), 60-73. http://dx.doi.org/10.1016/j.ijpe.2007.02.051.

Gupta, M. C. (1995). Environmental management and its impact on the operations function. International Journal of Operations \& Production Management, 15(8), 34-51. http://dx.doi.org/10.1108/01443579510094071.

Haanaes, K., Reeves, M., von Streng, V. I., Audretsch, M., Kiron, D., \& Kruschwitz, N. (2012). Sustainability nears a tipping point. Cambridge: MIT Sloan Management Review. Recuperado em 25 de outubro de 2013, de http://sloanreview.mit.edu/reports/sustainability-strategy/ organizational-support-performance/
Hall, R. H. (2004). Organizações - estruturas, processos e resultados (8. ed.). São Paulo: Prentice Hall.

Hanna, M. D., Newman, W. R., \& Johnson, P. (2000). Linking operational and environmental improvement through employee involvement. International Journal of Operations \& Production Management, 20(2), 148165. http://dx.doi.org/10.1108/01443570010304233.

Jabbour, C. J. C. (2009). Managing quality for environmental excellence: strategies, outcomes and challenges in Brazilian companies. Environmental Quality Management, 18(4), 65-71. http://dx.doi.org/10.1002/tqem.20226.

Jabbour, C. J. C., \& Santos, F. C. A. (2006). Evolução da gestão ambiental na empresa: uma taxonomia integrada à gestão da produção e de recursos humanos. Gestão \& Produção, 13(3), 435-448. http://dx.doi.org/10.1590/ S0104-530X2006000300007.

Kahn, K. B. (2001). Market orientation, interdepartmental integration, and product development performance. Journal of Product Innovation Management, 18(5), 314323. http://dx.doi.org/10.1016/S0737-6782(01)00101-1.

Kleindorfer, P. R., Singhal, K., \& Van Wassenhove, L. N. (2005). Sustainable operations management. Production and Operations Management, 14(4), 53-87.

Krackhardt, D., \& Hanson, J. (1993). Informal networks: The company behind the chart. Harvard Business Review, 71(4), 104-111.

Lombardi, G. H. V., Silva, A. L., \& Pimenta, M. L. (2012). Integração entre marketing, logística e produção: um estudo exploratório nos pontos de contato. In Anais do XV SIMPOI (pp. 1-16). São Paulo: FGV.

Morrow, D., \& Rondinelli, D. (2002). Adopting corporate environmental management systems: motivations and results of ISO 14001 and EMAS certification. European KManagement Journal, 20(2), 159-171.

Nash, H. A. (2009). The European Commission's sustainable consumption and production and sustainable industrial policy action plan. Journal of Cleaner Production, 17(4), 496-498. http://dx.doi.org/10.1016/j.jclepro.2008.08.020.

Porter, M. E., \& Van der Linde, C. (1995). Green and competitive: ending the stalemate. Harvard Business Review, 73(5), 120-134.

Pun, K. F. (2006). Determinants of environmentally responsible operations: a review. International Journal of Quality \& Reliability Management, 23(3), 279-297. http://dx.doi.org/10.1108/02656710610648233.

Rank, O. N. (2008). Formal structures and informal networks: structural analysis in organizations. Scandinavian Journal of Management, 24(2), 145-161. http://dx.doi. org/10.1016/j.scaman.2008.02.005.

Rossi, M. T. B., \& Barata, M. M. L. (2009). Barriers to the implementation of cleaner production as ecoefficiency practice in small and medium enterprises in the State of Rio de Janeiro. In Proceedings of the II International Workshop in Advances in Cleaner Production. São Paulo: UNIP. 
Simpson, D., \& Samson, D. (2010). Environmental strategy and low waste operations: exploring complementarities. Business Strategy and the Environment, 19(2), 104-118.

Sobral, F., \& Peci, A. (2008). Administração: toeria e prática no contexto brasileiro (1. ed.). São Paulo: Pearson Prentice Hall.

Stevenson, W. J. (2011). Operations management (11. ed.). Chicago: McGraw-Hill.

Tang, C. S. (2010). A review of marketing-operations interface models: from co-existence to coordination and collaboration. International Journal of Production Economics, 125(1), 22-40. http://dx.doi.org/10.1016/j. ijpe.2010.01.014.

Vasconcellos, E., \& Hemsley, J. R. (2002). Estrutura das organizações (4. ed.) São Paulo: Thomson Pioneira.
Wagner, M. (2007). Integration of environmental management with other managerial functions of the firm: empirical effects on drivers of economic performance. Long Range Planning, 40(6), 611-628. http://dx.doi.org/10.1016/j. lrp.2007.08.001.

Williams, J. A. S. (2007). Positive trends and opportunities for sustainable design in operations management in textbooks. In Proceedings of the IEEE International Symposium on Electronics and the Environment (pp. 57-60). Orlando: IEEE.

Xiong, G. (2011). Study on production logistics based on SCM integration models. Communications in Computer and Information Science, 211(4), 315-321. http://dx.doi. org/10.1007/978-3-642-23062-2_47.

Yin, R. K. (2010). Estudo de caso: planejamentos e métodos (4. ed.). Porto Alegre: Bookman. 